\title{
Green Manufacturing: Relationship between Adoption of Green Operational Practices and Green Performance of Brazilian ISO 9001-Certified Firms
}

\author{
Davi Fouad Soubihia', Charbel José Chiappetta Jabbour',", and Ana Beatriz Lopes de Sousa Jabbour' \\ 1 Department of Production Engineering, UNESP - University Estadual Paulista (Sao Paulo State University), Av. Eng. Ed. C. Coube, 14-01, Bauru, SP, Brazil, 17033360 \\ \# Corresponding Author / E-mail: prof.charbel@gmail.com, TEL: +551431036122, FAX: +551431036122
}

KEYWORDS: Green operations management, Environmental management, Emerging economies, Green management

\begin{abstract}
The present work aims at analyzing how the adoption of a proactive environmental management via green operational practices (GOPs) correlates to the Green Performance (GrP) of a given set of ISO 9001-certified firms in Brazil. To this end, we elaborated a conceptual framework about environmental management, GOPs, and GrP. Such theoretical foundation supported the development of empirical research through quantitative analysis. For the analysis, 75 questionnaires were collected from ISO 9001 certified companies. Data was analyzed by with statistical tools such as descriptive analysis, correlation analysis, and Structural Equation Modeling (SEM). The results demonstrate that the adoption of GOPs, in fact, exerts a positive impact on the GrP of the firms. This work contributes to a better understanding of green manufacturing in Brazil's industrial sector.
\end{abstract}

Manuscript received: October 15, 2014 / Revised: November 8, 2014 / Accepted: November 25, 2014

\begin{tabular}{l} 
NOMENCLATURE \\
GOPs $=$ Green Operational Practices \\
$\mathrm{GrP}=$ Green Performance \\
\hline
\end{tabular}

\section{Introduction}

The relevance of considering environmental aspects in the business context can be easily found in the current literature. Commitment to the environment has become a key variable in the contemporary competitive scenario. ${ }^{1-3}$ Companies recognize the fact that even though the process of implementing environmental strategies is unclear, environmental sustainability has implications for their competitive positions. ${ }^{4}$ There is a growing interest of managers, customers, employees and academics regarding marketing strategies focused on the environment. ${ }^{5}$ In addition, the authors emphasize that the companies can benefit from such strategies at different levels. Environmental management systems are positively related to business performance, especially long-term measures such as market share, image, and competitive advantage. ${ }^{6}$ In this sense, studies contribute to corroborate the above statement. ${ }^{7,8}$

The specialized literature highlights the importance of environmental pro-activity, through the adoption of a series of environmental practices and, in the same way, the GrP. In this sense, those practices fall into three groups: ${ }^{9}$ Organizational Environmental Practices; Communicational environmental practices and GOPs. The latter group has the greatest direct influence on environmental impacts generated by firms. These GOPs are the focus of this work. But are these practices related to an improved GrP in Brazilian firms with ISO 9001?

Thus, the following research question follows: Does the adoption of GOPs by Brazilian companies certified with ISO 9001 influence their GrP? As a consequence, the main purpose of this study is to investigate whether the adoption of environmental GOPs by Brazilian companies certified with ISO 9001 influences the GrP of these organizations. To achieve this objective, a survey was conducted and a research hypothesis was tested using Structural Equation Modeling (SEM).

\section{Theoretical Framework and Hypothesis Development}

In reference to the last evolutionary stage of Environmental 
Management, González-Benito and González-Benito ${ }^{9}$ understand Environmental Proactivity as the voluntary implementation of initiatives and practices seeking to improve GrP in an organization. From this standpoint, the authors divided the practices into three groups as follows:

- Green Organizational and Planning Practices: reflecting the extent to which the environmental management system had been developed and implemented, referring to the degree to which the company has defined its environmental policy, developed procedures for establishing environmental objectives, and actions alike. The authors claim that the system itself is not able to mitigate environmental impact.

- Green communicational practices: seeking to communicate the organization's actions regarding the environment, social and institutional environments. Once again, the authors point out that this set of practices by itself does not bring improvements to the $\mathrm{GrP}$ of the organization. Instead, such approaches seek business objectives and relationship-improving goals towards the firm's various stakeholders.

- Green Operational Practices (GOPs): the primary focus of this study. This set of practices entails changes in the production system and operations, which plays a key role in environmental issues. The authors, in their other work González-Benito and González-Benito, ${ }^{8}$ divided the group into two parts, the operational practices of product, process and practices, regarding "what" and "how." Then, according to the study, the operational practices focus on product design and development of more environmentally suitable products. Therein, the Process practices seek to develop and implement operational and manufacturing processes to reduce environmental impact.

With a focus on the GOPs, it is possible to highlight the following items/variables $(\mathrm{V})$ :

- Replacement of either polluting or hazardous materials or components (V1).

- Product development focused on reducing both material consumption and waste generation during the production and distribution / consumption (V2).

- Product development focused on reducing material consumption and waste generation during consumption (V3).

- Production process designed to focus on reducing the consumption of energy and resources (V4).

- Production Planning and Control focused on reducing waste and optimizing material consumption (V5).

- Acquisition of cleaner technologies and equipment (V6).

- Preferential purchasing of green products (V7).

- Environmental criteria in supplier selection (V8).

- Selection of less polluting means of transport (V9).

- Reusable or recyclable packaging in logistics activities (V10).

- Emission filters and pollution controls at the end of the production process (V11).

These practices can conduct firms to a better GrP. Lopez-Gamero et al. ${ }^{10}$ argue that $\mathrm{GrP}$ relates to the proactive environmental management, as well as the end-of-pipe approach. That is because the environmental impacts that firms cause can be reduced in a proactive way, as well as via reactive procedures. According to these authors, the term refers to

\section{Brazilian Context}

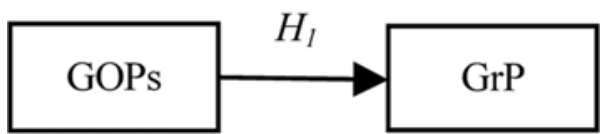

Fig. 1 Research framework

undesired outputs from the production process.

According to Henri and Journeault, ${ }^{11}$ the GrP indicators represent quantitative measures that provide key information relating to environmental matters. Moreover these indicators quantify the efficiency and effectiveness of environmental actions by following a series of metrics.

These indicators represented by the following items/variables $(\mathrm{V})$ :

- Reduction of Gas Emissions (V12).

- Reduction of Water Consumption (V13).

- Reduction of Solid Waste (V14).

- Reduction of Electricity/Power Comsuption (V15).

- Reduction of Consumption of hazardous / toxic materials (V16).

- Reduction of Environmental accidents (V17).

- Overall Environmental situation (V18).

Thus, given the above, it reinforces the hypothesis that the adoption of GOPs by Brazilian companies certified to ISO 9001 is positively related to superior GrP (Fig. 1). Thus:

$\mathrm{H}_{1}$ - GOPs are positively related to a better GrP in firms with ISO9001.

\section{Research Methodology}

Based on the research gap concerning the relationship of adopting GOPs and GrP, it was decided to conduct a study based on the assumptions of the quantitative analysis method. Therefore, we chose this methodology because the specialized literature provides previously existing quantitative scales for all the individual concepts analyzed. Therefore, the chosen methods allow one to conduct a survey on either an individual or the social unit to which they belong. ${ }^{12}$

The sample composition of this study includes Brazilian companies from industrial sector. The responding companies were selected from a database of The National Institute of Metrology, Standardization and Industrial Quality (INMENTRO) as certification bodies for a myriad of industries must be accredited by that entity. In the present study, we used the ISO 9001 certification, which is linked to quality management as a filter for selecting participants. Essentially, the choice is justified for one can find evidence that firms that have the ISO 9001 certification would be more likely to adopt environmental practices. ${ }^{13}$

Based on the theoretical framework (Section 2), an e-questionnaire was developed containing questions regarding the two sets of variables analyzed in this work. The groups of variables analyzed, herein referred to as GOPs and GrP, are represented by a series of themes drawn from the studies reviewed (Section 2).

We used a five-point Likert scale where "one" represents "Totally not implemented" and "five" stands for "Fully implemented" in the case of GOPs (V1-V11). In terms of GrP (V12-V18), each question refers to the perception of the leader of the company upon 
Table 1 Main statistics

\begin{tabular}{cccccc}
\hline & AVE & $\begin{array}{c}\text { Composite } \\
\text { reliability }\end{array}$ & R & $\begin{array}{c}\text { Cronbach's } \\
\text { Alpha }\end{array}$ & Communality \\
\hline GrP & 0.63492 & 0.923767 & 0.67580 & 0.90307 & 0.63492 \\
\hline GOPs & 0.57913 & 0.937435 & - & 0.92567 & 0.57913 \\
\hline
\end{tabular}

Table 2 Cross-loadings

\begin{tabular}{ccc}
\hline Items/Variables & GrP & GOPs \\
\hline V1 & 0.592977 & 0.732555 \\
\hline V2 & 0.654461 & 0.810585 \\
\hline V3 & 0.631405 & 0.780107 \\
\hline V4 & 0.496974 & 0.533982 \\
\hline V5 & 0.716512 & 0.835061 \\
\hline V6 & 0.584714 & 0.788902 \\
\hline V7 & 0.573368 & 0.753406 \\
\hline V8 & 0.656456 & 0.807262 \\
\hline V9 & 0.664849 & 0.744836 \\
\hline V10 & 0.624559 & 0.788238 \\
\hline V11 & 0.64628 & 0.753658 \\
\hline V12 & 0.784624 & 0.662503 \\
\hline V13 & 0.867449 & 0.686295 \\
\hline V14 & 0.831422 & 0.656446 \\
\hline V15 & 0.804419 & 0.608734 \\
\hline V16 & 0.832069 & 0.706671 \\
\hline V17 & 0.691486 & 0.564404 \\
\hline V18 & 0.753333 & 0.682102 \\
\hline & &
\end{tabular}

environmental improvements. This part of the questionnaire would be expressed so that "one" represents "Strongly Disagree" and "five" represents "strongly agree" as it incurred on the existence of the improvements.

The chosen tool for data collection consists of a questionnaire inserted in a virtual environment, through a website that allows hosting questionnaires from several modalities. At the end of this process, more than 1,000 questionnaires were sent, with a total of 75 respondents.

The data collected in the present work were analyzed using the statistical tool referred to as Structural Equation Modeling (SEM). Structural equation modeling is a second-generation multivariate statistical analysis method that has been gaining attention in the area of green management.

\section{Research Results}

Table 1 displays the values of the indicators of quality of the proposed model: Average Variance Extracted (AVE), Composite Reliability, $\mathrm{R}^{2}$ (coefficient of determination), Cronbach's Alpha and communalities. All of them are adequate.

For instance, by analyzing the Cross Loadings results, it was noted that all variables showed a greater load on the construct theoretically predicted (Table 2).

Also, it is noted that in the GOPs construct, all loadings are positive and greater than 0.5 , with only one lesser than 0.7 . Those of greater magnitude are:

- Production Planning and Control focused on reducing waste and optimizing material consumption (V5): 0.83

- Product development focused on reducing both material consumption and waste generation during the production and distribution/ consumption (V2): 0.81

- Environmental criteria in supplier selection (V8): 0.80

In the GrP group, all loadings are positive and greater than 0.6 , with a prevalence of values greater than 0.8 . Variables with loads of greater magnitude in this group are:

- Reduction of Water Consumption (V13): 0.86

- Reduction of Consumption of hazardous / toxic materials (V16): 0.83

- Reduction of Solid Waste (V14): 0.83

The path coeficient of the latent variables is 0.82 , indicating that the GOPs construct is positively related to the construct GrP, with a coefficient of determination $\left(\mathrm{R}^{2}\right)$ of 0.67 , which is considered intense. ${ }^{14}$

The result Bootstrapping test of the modeling, aiming assist the significance of the coefficient. Once all values are greater than 2.58 , one can observe a significance of $99 \%$ (p-value $<0.01$ ), (HAIR et al., 2011). Therefore, it can be stated that there is a high statistical significance in the model used.

Thus, it can be concluded that $\mathrm{H} 1$ is positive and significant

\section{Discussions}

As noted earlier, the statistical tool adopted in this research resulted in the value of $\mathrm{R}^{2}$ of 0.67 . This figure indicates that $67 \%$ of $\mathrm{GrP}$ can be explained by the adoption of GOPs. In short, it can be stated that the confirmation of the hypothesis brings strength to indications from the literature. That is because, in principle, most of the GrP derives from the adoption of GOPs. Such result confirms previous research. ${ }^{11}$ That the major responsibility of the environmental impacts of a company converges towards the operational practices. Therefore, the above reinforces the arguments of literature indicating that companies can benefit from the adoption of environmental management practices in becoming "green and competitive" firms. ${ }^{15}$ These findings also contribute with the current literature on green manufacturing in developing countries. ${ }^{16,17}$

\section{Conclusions}

In fact, the adoption of GOPs by Brazilian companies certified with ISO 9001 influences the result of the GrP of these organizations. Markedly, the research results showed that the before-mentioned influence occurs positively and with high significance.

The implications of this work in the academic sphere are as follows: initially, it may be emphasized that the hypothesis in question had not yet been tested by the specialized literature in the Brazilian context and with a sample of ISO 9001 firms. Since Brazil is a newly developed country, a member of the BRICs, the importance of studying the reality of the country is crucial. Thus, this work adds new evidence to the literature on green manufacturing. ${ }^{16,17}$ Accordingly, this paper also brings light on the degree of implementation of environmental practices in some Brazilian firms. For instance, one can observe that those practices have not been heavily adopted. Lastly, this study emphasized the high importance of saving water as an indicator of GrP. Disregarded 
by the literature, the variable stood out as a key factor in this work. Furthermore, the indication of the importance of this variable can be considered a contribution to the academy for future studies, which should adopt the indicator.

The main managerial implication of this paper lies in considering the low adoption of GOPs in the surveyed firms. In this sense, managers should understand the reasons for this phenomenon. Although the practices are not adopted in a comprehensive way, they provide great benefits, as reported in this study. Finally, since human resource management is considered a key factor for the adoption of best proactive environmental management, managers should concern in preparing employees for such a change. ${ }^{18,19}$ Future research is also necessary not only to analyze the "green dimension" but also others dimensions of a more sustainable manufacturing. ${ }^{20}$

\section{REFERENCES}

1. Molina-Azorín, J. F., Claver-Cortés, E., Pereira-Moliner, J., and Tarí, J. J., "Environmental Practices and Firm Performance: An Empirical Analysis in the Spanish Hotel Industry," Journal of Cleaner Production, Vol. 17, No. 5, pp. 516-524, 2009.

2. Labuschagne, C., Brent, A. C., and van Erck, R. P., "Assessing the Sustainability Performances of Industries," Journal of Cleaner Production, Vol. 13, No. 4, pp. 373-385, 2005.

3. Figge, F., Hahn, T., Schaltegger, S., and Wagner, M., "The Sustainability Balanced Scorecard-Linking Sustainability Management to Business Strategy," Business Strategy and the Environment, Vol. 11, No. 5, pp. 269-284, 2002.

4. Yang, M. G. M., Hong, P., and Modi, S. B., "Impact of Lean Manufacturing and Environmental Management on Business Performance: An Empirical Study of Manufacturing Firms," International Journal of Production Economics, Vol. 129, No. 2, pp. 251-261, 2011.

5. Cronin Jr, J. J., Smith, J. S., Gleim, M. R., Ramirez, E., and Martinez, J. D., "Green Marketing Strategies: An Examination of Stakeholders and the Opportunities They Present," Journal of the Academy of Marketing Science, Vol. 39, No. 1, pp. 158-174, 2011.

6. Agan, Y., Acar, M. F., and Borodin, A., "Drivers of Environmental Processes and Their Impact on Performance: A Study of Turkish SMEs,” Journal of Cleaner Production, Vol. 51, pp. 23-33, 2013.

7. Aragon-Correa, J. A. and Rubio-López, E. A., "Proactive Corporate Environmental Strategies: Myths and Misunderstandings," Long Range Planning, Vol. 40, No. 3, pp. 357-381, 2007.

8. González-Benito, J. and González-Benito, Ó., "Environmental Proactivity and Business Performance: An Empirical Analysis," Omega, Vol. 33, No. 1, pp. 1-15, 2005.

9. González-Benito, J. and González-Benito, Ó., "A Review of Determinant Factors of Environmental Proactivity," Business Strategy and the Environment, Vol. 15, No. 2, pp. 87-102, 2006.
10. López-Gamero, M. D., Molina-Azorín, J. F., and Claver-Cortes, E., "The Whole Relationship between Environmental Variables and Firm Performance: Competitive Advantage and Firm Resources as Mediator Variables," Journal of Environmental Management, Vol. 90, No. 10, pp. 3110-3121, 2009.

11. Henri, J.-F. and Journeault, M., "Environmental Performance Indicators: An Empirical Study of Canadian Manufacturing Firms," Journal of Environmental Management, Vol. 87, No. 1, pp. 165-176, 2008.

12. Forza, C., "Survey Research in Operations Management: A ProcessBased Perspective," International Journal of Operations \& Production Management, Vol. 22, No. 2, pp. 152-194, 2002.

13. Zhu, Q., Cordeiro, J., and Sarkis, J., "Institutional Pressures, Dynamic Capabilities and Environmental Management Systems: Investigating the ISO 9000-Environmental Management System Implementation Linkage," Journal of Environmental Management, Vol. 114, pp. 232-242, 2013.

14. Hair, J. F., Ringle, C. M., and Sarstedt, M., "PLS-SEM: Indeed a Silver Bullet," The Journal of Marketing Theory and Practice, Vol. 19, No. 2, pp. 139-152, 2011.

15. Porter, M. E. and van der Linde, C., "Green and Competitive: Ending the Stalemate," Harvard Business Review, Vol. 73, No. 5, pp. 120-134, 1995.

16. Govindan, K., Kannan, D., and Shankar, M., "Evaluation of Green Manufacturing Practices using a Hybrid MCDM Model Combining DANP with PROMETHEE," International Journal of Production Research, pp. 1-28, http://www.tandfonline.com/doi/abs/10.1080/ 00207543.2014.898865\#.VIEMBSxxk7Y (Accessed 5 December 2014)

17. Govindan, K., Diabat, A., and Madan Shankar, K. "Analyzing the Drivers of Green Manufacturing with Fuzzy Approach,” Journal of Cleaner Production, pp. 1-14, http://www.sciencedirect.com/science/ article/pii/S0959652614002005 (Accessed 5 December 2014)

18. Jackson, S. E., Renwick, D. W., Jabbour, C. J., and Müller-Camen, M., "State-of-the-Art and Future Directions for Green Human Resource Management: Introduction to the Special Issue," Zeitschrift für Personalforschung (ZfP), Vol. 25, No. 2, pp. 99-116, 2011.

19. Ehnert, I., "Sustainability and Human Resource Management: Reasoning and Applications on Corporate Websites," European Journal of International Management, Vol. 3, No. 4, pp. 419-438, 2009.

20. Herrmann, C., Schmidt, C., Kurle, D., Blume, S., and Thiede, S., "Sustainability in Manufacturing and Factories of the Future," Int. J. Precis. Eng. Manuf.-Green Tech., Vol. 1, No. 4, pp. 283-292, 2014. 